\title{
A review of the critical success factors in the adoption of lean production system by small and medium sized enterprises
}

\begin{abstract}
Small and Medium-sized Enterprises (SMEs) are important contributors to the economy of a country. In recent years, due to globalization and competition in the market they have faced high pressure to survive in the market. Lean production as a method of cost reduction which improves the efficiency has been adopted by many SMEs to survive within these dynamic markets. However, many failures of implementing a successful lean production system have been reported, caused by the inherent limitations of and factors unique to SMEs. This paper reviewed studies that focused on the Critical Success Factors (CSFs) of implementing lean production among SMEs. The result of the study highlighted that lack of top management commitment, cultural change, education and training might hinder the implementation of lean production in SMEs successfully.
\end{abstract}

Keyword: Critical success factors; Lean manufacturing; Small and medium-sized enterprises 